ISSN: 1808-8759

\title{
AVALIAÇÃO DA CULTURA DO MILHO SUBMETIDA À HORMESIS
}

\author{
Saulo Fernando Gomes de Sousa ${ }^{1}$, Paulo Roberto Arbex Silva ${ }^{2}$ \& Sérgio Hugo Benez
}

\begin{abstract}
RESUMO: Nos sistemas conservacionistas de preparo do solo é fundamental a manutenção de resíduos vegetais das culturas anteriores na superfície do solo. A técnica denominada Hormesis visa aumentar a quantidade de palha e também provocar um atraso na decomposição da palha. Assim sendo o presente trabalho objetivou valiar as características agronômicas da cultura do milho em sistema de plantio direto submetida a Hormesis. O experimento foi na Faculdade de Ciências Agronômicas - UNESP/Botucatu, SP. O delineamento experimental utilizado foi o de blocos inteiramente casualizados. Os tratamentos utilizados baseados na técnica de Hormesis foram: Testemunha (sem aplicação), Gliphosate sub dosagem baixa (12,5 g.ia.ha $\left.{ }^{-1}\right)$, Gliphosate sub dosagem média (25 g.ia.ha $\left.{ }^{-1}\right)$, Gliphosate sub dosagem alta (50 g.ia.ha $\left.{ }^{-1}\right), 2,4-D$ sub dosagem baixa (100 g.ia.ha $\left.{ }^{-1}\right), 2,4-D$ sub dosagem média $\left(200\right.$ g.ia.ha $\left.{ }^{-1}\right)$, 2,4-D sub dosagem alta $\left(300\right.$ g.ia.ha $\left.{ }^{-1}\right)$, Verdict sub dosagem baixa $\left(0,625\right.$ g.ia.ha $\left.{ }^{-1}\right)$, Verdict sub dosagem média $(1,25$ g.ia.ha $\left.{ }^{1}\right)$, Verdict sub dosagem alta $\left(2,5\right.$ g.ia.ha $\left.{ }^{-1}\right)$. Foram avaliadas na cultura do milho as seguintes características agronômicas: altura de planta e de inserção da primeira espiga, diâmetro de colmo, comprimento de espiga, número de fileiras de espiga, diâmetro de espiga, peso hectolitrico, porcentagem de grãos na espiga, massa de matéria seca da planta e produtividade. Os resultados encontrados mostraram que para todos os tratamentos avaliados não houve diferença estatística, ou seja, nas condições de campo em que o experimento foi realizado, aliadas as condições climáticas ocorridas no período da realização do mesmo a cultura do milho não foi afetada com as aplicações das sub dosagens dos herbicidas.
\end{abstract}

PALAVRAS CHAVE: Plantio direto, sistemas conservacionistas, herbicida.

\section{EVALUATION OF MAIZE SUBMITTED TO HORMESIS}

ABSTRACT: Under conservation tillage systems is critical to maintaining plant residues from previous crops on the soil surface. A technique called Hormesis aims to increase the amount of straw and also cause a delay in straw decomposition. Therefore, this study aimed to evaluate the agronomic characteristics of corn under no-tillage system subjected to Hormesis. The experiment was carried out at UNESP campus in the city of Botucatu, SP . The experimental was design in completely randomized blocks. The treatments based on the technique of Hormesis were : control (no application), sub Gliphosate low dosage (12.5 g.ai.ha ${ }^{-1}$ ), sub Gliphosate average dosage (25 g. ai.ha $\left.{ }^{-1}\right)$, sub Gliphosate high dose (50 g. ai.ha $\left.{ }^{-1}\right), 2,4-D$ under low dose (100 g. ai.ha $\left.{ }^{-1}\right), 2,4-D$ sub average dosage (200 g. ai.ha $\left.{ }^{-1}\right)$ 2,4- D under high dosage (300 g. ai.ha $\left.{ }^{-1}\right)$ sub Verdict low dose $\left(0.625\right.$ g. ai.ha $\left.{ }^{-1}\right)$ sub Verdict average dosage $\left(1.25\right.$ g. ai.ha $\left.{ }^{-1}\right)$, sub Verdict high dosage $\left(2.5 \mathrm{~g}\right.$. ai.ha $\left.{ }^{-1}\right)$. In addition, the following characteristics were evaluated: plant height, first ear growth, stem diameter, ear length, number of rows per cob, cob diameter, , percentage of grains on the cob, mass of plant dry matter, and yield. The results showed that all the treatments showed no statistical difference, the maize was not affected with sub doses of herbicides applications under the field and weather conditions in which the experiment was conducted.

KEYWORDS: No tillage, conservation systems, herbicides.

\section{INTRODUÇÃO}

$\mathrm{Na}$ agricultura conservacionista e principalmente no sistema de plantio direto a manutenção dos resíduos vegetais sobre o solo é essencial, pois entre outros fatores

${ }^{1}$ Faculdade de Ciências Agronômicas/UNESP. Departamento de Engenharia rural - Sub area Mecanização Agrícola. E-mail: saulo@fca.unesp.br

${ }_{2}^{2}$ Faculdade de Ciências Agronômicas/UNESP. Departamento de Engenharia rural - Sub area Mecanização Professor Adjunto Departamento de Engenharia rural. E-mail: arbex@fca.unesp.br

3 Faculdade de Ciências Agronômicas/UNESP. Professor titular -

Departamento de Engenharia rural. E-mail: benez@fca.unesp.br funciona como um reservatório de nutrientes que lentamente são liberados para as plantas, por meio da ação de microorganismos. A eficácia dos preparos conservacionistas de solo, especialmente a semeadura direta, está relacionada, com a quantidade de resíduos 
culturais e com a cobertura superficial do solo (FERNANDES, 2009).

Para a consolidação do sistema de plantio direto é muito importante a implantação de culturas que deixam grande quantidade de palhada sobre a superfície do solo. Em regiões mais quentes ainda hoje há uma grande dificuldade de se implantar o plantio direto, devido a dificuldade de se conseguir manter a palhada de um ano pra outro, por esta se decompor muito rapidamente (ANDREOTTI, et al. 2008).

Para Bertol et al., (1998) o conhecimento dessa velocidade de decomposição dos resíduos vegetais, ajuda para um planejamento de praticas conservacionistas que visam otimizar os benefícios desses resíduos durante períodos críticos.

A consequência da permanência desses resíduos vegetais sobre os solo é a manutenção ou ainda o aumento da matéria orgânica, o que levando a uma maior disponibilidade de nutrientes para as culturas subsequentes, como o Fósforo (P), Potássio (K), Cálcio (Ca) e Magnésio (Mn) (PAVINATO E ROSOLEM, 2008), sem falar nas melhorias dos atributos físicos, não nos esquecendo da redução nos riscos de erosão (ANDRADE et al, 2009).

Porem se essa decomposição for muito demorada, a disponibilidade de nutriente da palhada para a cultura ali implantada ficará prejudicada (AMADO et al., 2003), esse sincronismo é um grande desafio para agricultores e técnicos envolvidos nessa área.

A permanência dos resíduos vegetais sobre o solo é definida pela sua velocidade de decomposição, a qual é uma variável importante no manejo do solo. Este processo é essencialmente biológico, sujeito à interferência de diversos fatores (clima, temperatura, tipo de solo, relação $\mathrm{C} / \mathrm{N}$ etc.), dentre esses a relação $\mathrm{C} / \mathrm{N}$ (carbono/nitrogênio) assume importante papel na decomposição e na imobilização/mineralização de $\mathrm{N}$ do solo (SANTI et al., 2003)

Portanto, é fundamental a seleção de espécies de coberturas vegetais com elevada capacidade de produção de massa seca, principalmente, em regiões onde as condições climáticas são favoráveis à rápida decomposição, além do estabelecimento de manejos da palhada que minimizem esse efeito, visando à proteção superficial do solo, formação de palhada, bem como reciclagem de nutrientes, com impacto direto nos atributos químicos do solo e na resposta das culturas subseqüentes ou em rotação (FERNANDES, 2008).

Uma das técnicas que vem sendo empregada com intuito de aumentar da quantidade de palha é a denominada técnica de Hormesis. Essa técnica prega que todas as substâncias são veneno e não veneno, o que faz dela letal ou não é apenas a dosagem (Aureolus Philippus Theophrastus Bombastus von Hohenheim, 1493-1541). O termo Hormesi foi primeiramente utilizado pelos autores
Southam e Erlich (1943) para descrever o efeito de um composto de casca de carvalho que promoveu o crescimento de fungos em baixas doses, porém, fortemente inibida em doses elevadas.

Atualmente, tanto no setor de produção agrícola quanto nas diversas áreas da saúde humana, o efeito de subdoses de produtos aplicados, denominado como hormótico, vem sendo amplamente discutido e pesquisado, com o objetivo de compreender o mecanismo de ação estimulante e benéfica de diversas substâncias inicialmente consideradas tóxicas (SILVA et al, 2009).

O herbicida glyphosate apresentou efeito hormético em plantas de milho e soja convencional, com aumentos na massa seca (Velini et al. 2008), na produtividade de cevada (Cedergreen et al. 2009) e algodão (Furlani Júnior et al. 2009), com aplicações de subdoses. Além do efeito hormético, o glyphosate, em pequenas doses, pode ser utilizado como regulador de crescimento, como observado em algodão (Neves et al. 2009) e em cana-deaçúcar (Leite e Crusciol 2008). As pequenas doses por área, o baixo custo do produto e a grande disponibilidade do ingrediente ativo no mercado são fatores que favorecem a utilização do glyphosate como regulador de crescimento.

Objetivou-se avaliar as características agronômicas, da cultura do milho em sistema de plantio direto submetido a técnica de Hormesis.

\section{MATERIAL E MÉTODOS}

O experimento foi conduzido no ano agrícola 2011/2012, na Fazenda Experimental Lageado, pertencente à Faculdade de Ciências Agronômicas - UNESP, localizada no município de Botucatu - SP, na região centro oeste do Estado de São Paulo, tendo como coordenadas geográficas aproximadas de Latitude $22^{\circ} 51^{\prime} \mathrm{S}$ e Longitude $48^{\circ} 26^{\prime} \mathrm{W}$ de Greenwich, altitude média de 770 metros, clima subtropical chuvoso, apresentando inverno seco, tipo $\mathrm{Cfa}$, de acordo com o critério de Köeppen.

A área experimental vinha sendo cultivada com sistema de plantio direto desde o ano 2000 , com rotação de soja e milho no verão e pousio no inverno para a produção de palha. No momento da realização dos preparos a área estava coberta com resíduos vegetais, sendo uma grande porcentagem desta pertencente à cultura do milho (Zea mays) cultivada anteriormente e a outra parte pertencente às plantas daninhas dessecadas.

As parcelas possuíam dimensões de $10 \mathrm{~m}$ de comprimento e $4 \mathrm{~m}$ de largura, comportando quatro linhas de semeadura espaçadas a $0,85 \mathrm{~m}$. Entre cada parcela foi deixado um espaço de $5 \mathrm{~m}$ de fundo e $3 \mathrm{~m}$ de lado onde também foram implantadas duas linhas de milho para evitarem contaminação entre parcelas.

O milho foi semeado o dia 21/11/11 com uma semeadora adubadora de precisão, para plantio direto, com 
espaçamento entre linhas de $0,85 \mathrm{~m}$. As sementes utilizadas no experimento, foram as do hibrido simples 2B 587 Hx da empresa Dow AgroSciences, a população utilizada foi de 70000 sementes por hectare, com uma adubação de base de $300 \mathrm{~kg} \cdot \mathrm{ha}^{-1}$ do formulado 08-28-16. A adubação de cobertura foi realizada em duas etapas a primeira 24 dias após a semeadura, onde foi aplicado 150 $\mathrm{kg}$. ha ${ }^{-1}$ de uréia, esta aplicação foi realizado com um cultivador-adubador, próprio para aplicações em áreas de plantio direto. A segunda aplicação foi realizada 48 dias após a semeadura, e dessa vez foi aplicado $100 \mathrm{~kg}$. ha ${ }^{-1}$, com o mesmo equipamento.

Para a pulverização dos herbicidas nas parcelas foi utilizado um pulverizador costal, pressurizado a $\mathrm{CO}_{2}$, mantendo-se a uma pressão constante de $2,0 \mathrm{kgf} . \mathrm{cm}^{2}$, e equipado com uma barra de aplicação de 2 metros munida com 4 pontas de pulverização Teejet XR 11002 VS espaçadas entre si de 0,5 metros.

As avaliações foram realizadas nas duas linhas centrais da parcela, utilizando-se $5 \mathrm{~m}$ de cada linha, totalizando assim $10 \mathrm{~m}$ avaliados de cada parcela. As medições de altura de planta e de inserção da primeira espiga e comprimento de espiga foram feitas com uma fita métrica graduada de $0,01 \mathrm{~m}$, já o diâmetro de colmo e de espiga foi realizado com um paquímetro digital com precisão de $0,001 \mathrm{~m}$.

A população inicial foi contada aos 20 dias após a semeadura, e a população final na mesma data da colheita, por meio destes dados foi feito o índice de sobrevivência da cultura.

A matéria seca foi determinada por meio da coleta de 5 plantas, sem as espigas, ao acaso dentro da área avaliada da parcela. De cada planta coletada foi separado o colmo do restante das palhas da planta e secas em estufa, em seguida, determinou-se a quantidade de matéria seca por hectare separadamente de colmo e de palha e depois somados para a determinação também da quantidade de palha total por hectare.

Para determinar a produtividade foram colhidas manualmente as espigas de todas as plantas presentes no espaço de cinco metros das duas linhas centrais de cada parcela. Essas espigas foram debulhadas por uma debulhadora estacionária de grãos, sendo em seguida determinado o peso de cada parcela por meio de uma balança. Após a pesagem foi tomada uma amostra de cada parcela e levadas ao laboratório para determinação da umidade da massa de grãos. As amostras foram pesadas e colocadas na estufa por 24 horas a $105^{\circ} \mathrm{C}$, sendo pesadas novamente para obtenção da produtividade de grãos corrigida para $13 \%$ de umidade.

Os resultados obtidos foram submetidos à análise de variância. Quando o teste $\mathrm{F}$ mostrou-se significativo a 5\% de probabilidade foi aplicado o teste de Tukey para comparação entre médias.

\section{RESULTADOS E DISCUSSÃO}

Não houve diferença estatística para os dados de populações iniciais, finais e índice de sobrevivência da cultura do milho para nenhum dos tratamentos avaliados (Tabela 1). Pode-se afirmar que os produtos aplicados nas plantas de milho não afetaram a cultura quanto a quantidade de plantas que chegaram ao final do ciclo.

Tabela 1 - Populações inicial, população final e índice de sobrevivência nos diferentes tratamentos.

\begin{tabular}{lccc}
\hline TRATAMENTOS & $\begin{array}{c}\text { População } \\
\text { inicial } \\
\left(\text { plantas.ha }^{-1}\right)\end{array}$ & $\begin{array}{c}\text { População } \\
\text { final } \\
\left(\text { plantas.ha }^{-1}\right)\end{array}$ & $\begin{array}{c}\text { Índice de } \\
\text { sobrevivência (\%) }\end{array}$ \\
\hline Testemunha & $66908 \mathrm{a}$ & $66540 \mathrm{a}$ & $99,47 \mathrm{a}$ \\
Gliphosate dosagem baixa & $64702 \mathrm{a}$ & $62128 \mathrm{a}$ & $95,99 \mathrm{a}$ \\
Gliphosate dosagem media & $64334 \mathrm{a}$ & $64334 \mathrm{a}$ & $100,00 \mathrm{a}$ \\
Gliphosate dosagem alta & $63232 \mathrm{a}$ & $62864 \mathrm{a}$ & $98,83 \mathrm{a}$ \\
2,4-D dosagem baixa & $65069 \mathrm{a}$ & $63967 \mathrm{a}$ & $98,22 \mathrm{a}$ \\
2,4-D dosagem media & $61393 \mathrm{a}$ & $60290 \mathrm{a}$ & $98,18 \mathrm{a}$ \\
2,4-D dosagem alta & $60290 \mathrm{a}$ & $58820 \mathrm{a}$ & $97,64 \mathrm{a}$ \\
Verdict dosagem baixa & $63967 \mathrm{a}$ & $63231 \mathrm{a}$ & $98,87 \mathrm{a}$ \\
Verdict dosagem media & $63599 \mathrm{a}$ & $62496 \mathrm{a}$ & $98,27 \mathrm{a}$ \\
Verdict dosagem alta & $62350 \mathrm{a}$ & $62128 \mathrm{a}$ & $99,48 \mathrm{a}$ \\
\hline CV $(\%)$ & 5,13 & 5,86 & 2,55 \\
\hline
\end{tabular}

Médias seguidas de mesma letra na coluna não diferem entre si pelo teste de Tukey, a $5 \%$ de probabilidade.

A população final de plantas sempre está ligada a população inicial, pois se a inicial apresentar uma grande variação consequentemente a final obrigatoriamente tem que apresentar também, uma vez que as duas estão interligadas. Em trabalho realizado por Silva (2004), também não houve diferença estatística na população final de plantas nos dois anos em que o experimento foi realizado. No citado experimento o autor avaliou quatro variedades diferentes de sementes de milho em dois espaçamentos entre linhas distintos.

Os dados de matéria seca do milho (Tabela 2) também não apresentaram diferença estatística nem na matéria 
seca da palha nem na do colmo e por consequência nem na matéria seca total da cultura após a colheita. Porém, pode-se observar que conforme foram aumentando as dosagens aplicadas de 2,4-D e Verdict, as quantidades de matéria seca também foram aumentando sequencialmente.

Tabela 2 - Matéria seca da palha, colmo e total em função das doses de produto.

\begin{tabular}{lccc} 
Tabela 2 - Matéria seca da palha, colmo e total em função das doses de produto. \\
\hline TRATAMENTOS & $\begin{array}{c}\text { Matéria seca da } \\
\text { palha }\left(\mathrm{kg}^{-1} \mathrm{ha}^{-1}\right)\end{array}$ & $\begin{array}{c}\text { Matéria seca do } \\
\text { colmo } \\
\left(\mathrm{kg}^{-1}\right)\end{array}$ & $\begin{array}{c}\text { Matéria seca Total } \\
\left(\mathrm{kg} \cdot \mathrm{ha}^{-1}\right)\end{array}$ \\
\hline Testemunha & $3334 \mathrm{a}$ & $3209 \mathrm{a}$ & $6544 \mathrm{a}$ \\
Gliphosate dosagem baixa & $3145 \mathrm{a}$ & $3051 \mathrm{a}$ & $6197 \mathrm{a}$ \\
Gliphosate dosagem media & $3723 \mathrm{a}$ & $3060 \mathrm{a}$ & $6783 \mathrm{a}$ \\
Gliphosate dosagem alta & $3407 \mathrm{a}$ & $2732 \mathrm{a}$ & $6140 \mathrm{a}$ \\
2,4-D dosagem baixa & $3203 \mathrm{a}$ & $3303 \mathrm{a}$ & $6506 \mathrm{a}$ \\
2,4-D dosagem media & $3589 \mathrm{a}$ & $3565 \mathrm{a}$ & $7154 \mathrm{a}$ \\
2,4-D dosagem alta & $3485 \mathrm{a}$ & $4085 \mathrm{a}$ & $7571 \mathrm{a}$ \\
Verdict dosagem baixa & $3154 \mathrm{a}$ & $2703 \mathrm{a}$ & $5857 \mathrm{a}$ \\
Verdict dosagem media & $3165 \mathrm{a}$ & $3060 \mathrm{a}$ & $6226 \mathrm{a}$ \\
Verdict dosagem alta & $3434 \mathrm{a}$ & $3945 \mathrm{a}$ & $7379 \mathrm{a}$ \\
\hline CV $(\%)$ & 15,29 & 25,06 & 17 \\
\hline
\end{tabular}

Médias seguidas de mesma letra na coluna não diferem entre si pelo teste de Tukey, a $5 \%$ de probabilidade.

Segundo Costa et al (2008) a quantidade de matéria seca principalmente a parte foliar é afetada significativamente quando a cultura sofre um estresse hídrico de 50 e $75 \%$ da necessidade de água necessária para seu desenvolvimento pleno, isso pode explicar a não diferença de incremento de matéria seca nesse trabalho, pelo fato da cultura ter sofrido dois períodos críticos de estresse hidrico. Outro fator que interfere no incremento de matéria seca da cultura do milho é o nível de saturação de bases (V\%) que se encontra no solo, sendo níveis ideais (70\%) a uma quantidade maior de matéria do que em níveis inferiores (15 e 50\%) (ANDREOTTI, 2001).

No presente trabalho não houve aplicação de herbicida seletivo para o controle de plantas daninhas, portanto houve de certo modo uma competição por nutrientes, água e luz com a cultura do milho. Em trabalho realizado por Silva, et al (2010) foi constatado que a aplicação de herbicida seletivo na cultura do milho afeta positivamente a produção de matéria seca da mesma em relação a tratamentos sem aplicação ou com capinas manuais, pois segundo os autores essas aplicações não afetam a cultura, por esta ser tolerante aos herbicidas, e tem controle mais eficaz sobre as plantas daninhas, diminuindo assim a competição por água, luz e nutrientes entre as mesmas.

Para os dados de altura de plantas aos 50 dias após a semeadura, no final do ciclo, altura de inserção da primeira espiga e diâmetro de colmo, não houve diferenças estatísticas. Como consequências a isso, podese inferir que as sub dosagens de herbicidas não afetam essas características da cultura do milho (Tabela 3).

Tabela 3 - Altura de plantas com 50 dias após a semeadura e no final do ciclo, altura de inserção da primeira espiga e diâmetro de colmo em função das doses de produto.

\section{TRATAMENTOS}

\begin{tabular}{l} 
Testemunha \\
Gliphosate dosagem baixa \\
Gliphosate dosagem media \\
Gliphosate dosagem alta \\
2,4-D dosagem baixa \\
2,4-D dosagem media \\
2,4-D dosagem alta \\
Verdict dosagem baixa \\
Verdict dosagem media \\
Verdict dosagem alta \\
\hline CV $(\%)$
\end{tabular}

\section{Altura de plantas} com 50 dias $(\mathrm{m})$

\section{Altura de plantas final}

(m)
Altura de inserção da primeira espiga

(m)
Diâmetro do colmo (mm)

Médias seguidas de mesma letra na coluna não diferem entre si pelo teste de Tukey, a 5\% de probabilidade.

Possamai et al. (2001) encontraram maiores alturas de plantas e de inserção de espiga no sistema de semeadura direta e atribuem isso ao fato de que as plantas no plantio direto estabeleceram-se primeiro, o que resultou em maior 
crescimento das plantas, fato que não aconteceu nesse trabalho, pois o presente trabalho foi instalado apenas em sistema de plantio direto.

Riquetti (2011) também não encontrou diferença nas alturas de plantas, de inserção da primeira espiga e nem no diâmetro de colmo. Em seu trabalho a cultura do milho foi avaliada em três preparos diferentes de solo e com dois híbridos de milho isogênico, transgênico e não transgênico.

Velini et al (2008) verificou estímulo no crescimento de soja, milho, Eucalyptus grandis, Pinus caribea e Commelina benghalinsis, quando aplicada nessas culturas sub dosagens de gliphosate, o autor ainda ressalta que para cada cultura foram utilizadas sub dosagens diferente. Avaliando o efeito hormético na cultura do algodoeiro Neves et al. (2009) chegaram a conclusão que com a aplicação de sub dosagens de gliphosate na cultura do algodão faz com que haja um crescimento de até $15 \%$ em relação as plantas testemunhas (sem aplicação), porém ambos os trabalhos foram realizados em casa de vegetação e portanto não faltou água fazendo com que o herbicida causasse o estímulo previsto nas culturas avaliadas.

O diâmetro da espiga, o comprimento da espiga e o número de fileiras na espiga, não apresentaram diferenças significativas (Tabela 4)

Tabela 4 - Diâmetro, comprimento e número de fileiras nas espigas de milho avaliadas em função das doses de produto.

\begin{tabular}{lccc}
\hline TRATAMENTOS & $\begin{array}{c}\text { Diâmetro de espiga } \\
(\mathrm{mm})\end{array}$ & $\begin{array}{c}\text { Comprimento de } \\
\text { espiga }(\mathrm{cm})\end{array}$ & Numero de fileiras \\
\hline Testemunha & $47,9 \mathrm{a}$ & $13,6 \mathrm{a}$ & $14,3 \mathrm{a}$ \\
Gliphosate dosagem baixa & $48,1 \mathrm{a}$ & $14,3 \mathrm{a}$ & $14,2 \mathrm{a}$ \\
Gliphosate dosagem media & $48,1 \mathrm{a}$ & $13,4 \mathrm{a}$ & $14,1 \mathrm{a}$ \\
Gliphosate dosagem alta & $47,7 \mathrm{a}$ & $13,5 \mathrm{a}$ & $14,4 \mathrm{a}$ \\
2,4-D dosagem baixa & $49 \mathrm{a}$ & $14,5 \mathrm{a}$ & $14,6 \mathrm{a}$ \\
2,4-D dosagem media & $49 \mathrm{a}$ & $14,7 \mathrm{a}$ & $14,4 \mathrm{a}$ \\
2,4-D dosagem alta & $48 \mathrm{a}$ & $14,8 \mathrm{a}$ & $14,3 \mathrm{a}$ \\
Verdict dosagem baixa & $48,1 \mathrm{a}$ & $13,9 \mathrm{a}$ & $14,2 \mathrm{a}$ \\
Verdict dosagem media & $48,1 \mathrm{a}$ & $14,2 \mathrm{a}$ & $14,3 \mathrm{a}$ \\
Verdict dosagem alta & $48,3 \mathrm{a}$ & $14,4 \mathrm{a}$ & $14,1 \mathrm{a}$ \\
\hline CV $(\%)$ & 2,12 & 5,47 & 2,73 \\
\hline
\end{tabular}

Médias seguidas de mesma letra na coluna não diferem entre si pelo teste de Tukey, a $5 \%$ de probabilidade.

As características da espiga do milho apresentaram baixo coeficiente de variação $(<10 \%)$ (PIMENTEL GOMES, 1990), e dessa forma demonstra boa precisão experimental (CARVALHO et al., 2003). Além também de ser uma característica dos milhos híbridos, por apresentarem uma baixa variação genética.

O comprimento e o diâmetro da espiga são características que interferem diretamente na produtividade de uma lavoura, afinal quanto mais comprida e mais grossa uma espiga a tendência é uma maior produção de grãos e por conseqüência uma maior produtividade.

Em relação aos dados de pesos hectolítricos as porcentagens de grãos nas massas totais das espigas e a produtividade por hectare não variaram estatisticamente, comprovando que a aplicação de sub dosagens de herbicida na cultura do milho não afeta a massa dos grãos e a produção por área (Tabela 5).

Tabela 5 - Peso hectolítrico, porcentagem de grãos na massa total da espiga e produtividade por hectare em função das doses de produto.

\begin{tabular}{lccc}
\hline TRATAMENTOS & $\begin{array}{c}\text { Peso hectolítrico (massa } \\
\text { em 100 l) }\end{array}$ & $\begin{array}{c}\text { Porcentagem de } \\
\text { grãos na massa total } \\
\text { da espiga (\%) }\end{array}$ & $\begin{array}{c}\text { Produtividade } \\
\left(\mathrm{kg} . \mathrm{ha}^{-1}\right)\end{array}$ \\
\hline Testemunha & $65,64 \mathrm{a}$ & $74 \mathrm{a}$ & $8791 \mathrm{a}$ \\
Glyphosate dosagem baixa & $64,53 \mathrm{a}$ & $74 \mathrm{a}$ & $8187 \mathrm{a}$ \\
Glyphosate dosagem media & $66,54 \mathrm{a}$ & $74 \mathrm{a}$ & $8436 \mathrm{a}$ \\
Glyphosate dosagem alta & $65,28 \mathrm{a}$ & $74 \mathrm{a}$ & $7880 \mathrm{a}$ \\
2,4-D dosagem baixa & $64,41 \mathrm{a}$ & $73 \mathrm{a}$ & $8420 \mathrm{a}$ \\
2,4-D dosagem media & $64,13 \mathrm{a}$ & $73 \mathrm{a}$ & $8537 \mathrm{a}$ \\
2,4-D dosagem alta & $64,88 \mathrm{a}$ & $72 \mathrm{a}$ & $7644 \mathrm{a}$ \\
Verdict dosagem baixa & $65,09 \mathrm{a}$ & $72 \mathrm{a}$ & $7856 \mathrm{a}$ \\
Verdict dosagem media & $65,19 \mathrm{a}$ & $73 \mathrm{a}$ & $8681 \mathrm{a}$ \\
Verdict dosagem alta & $65,54 \mathrm{a}$ & 2,7 & $7926 \mathrm{a}$ \\
\hline CV $(\%)$ & 1,63 & 8,74 \\
\hline
\end{tabular}

Médias seguidas de mesma letra na coluna não diferem entre si pelo teste de Tukey, a 5\% de probabilidade. 

Furlani Jr et al. (2009) notaram um aumento significativo no número de capulhos e consequentemente na produção de algodão quando aplicado sub dosagens de gliphosate, o maior incremento se deu quando foi aplicado a dosagem de 20 g.ha.i.a. ${ }^{-1}$. Porém, como já citado acima também nesse trabalho as condições climáticas foram controladas, portanto os herbicidas tiveram plenas condições de agirem nas plantas.

Figueiredo et al. (2007), constataram que a aplicação de sub dosagens de gliphosate na cultura do tomate afeta de forma negativa seu desenvolvimento e também sua produção a partir da dosagem de $378 \mathrm{~g} \cdot \mathrm{ha}^{-1}$. Outros efeitos negativos foram encontrados nas culturas de milho (ALVES, 2000), sorgo (MAGALHÃES et al., 2001 a, b), algodão (YAMASHITA E GUIMARÃES, 2005) e eucalipto, em que a intoxicação das plantas resultou em redução de crescimento e produtividade (TUFFI SANTOS et al., 2006)

Silva et al. (2012), avaliou a cultura do feijoeiro quando submetido a aplicação de sub dosagens de Gliphosate, em seu trabalho foram avaliadas três cultivares de feijão, para nenhuma delas a produtividade foi afetada, porém a massa de 100 grãos foi afetada negativamente.

\section{CONCLUSÃO}

Nas condições em que o experimento foi realizado não observou-se nenhuma variação nas características agronômicas e nem na produtividade da cultura do milho.

\section{REFERÊNCIAS}

ALVES, L. W. R.; SILVA, J. B.; Efeito da aplicação de subdoses dos herbicidas glyphosate e oxyfluorfen, simulando deriva sobre a cultura do milho (Zea mays L.). Ciência Agrotecnologia, Lavras, v. 24, p. 889-897, 2000 .

AMADO, T. J. C.; SANTI, A.; ACOSTA, J. A. A. Adubação nitrogenada na aveia preta. II - Influência na decomposição de resíduos, liberação de nitrogênio e rendimento de milho sob sistema plantio direto. Revista Brasileira de Ciência do Solo, Viçosa, v. 27, p. 1085 1096, 2003.

ANDRADE, S. R.; STONE, L. F.; SILVEIRA, P. M. Culturas de cobertura e qualidade fisoca de um latossolo em plantio direto. Revista Brasileira de Engenharia Agrícola e Ambiental, Campina Grande, v. 13, n. 4, p. 411-418, 2009

ANDREOTTI, M.; ARALDI, M.; GUIMARAES, V. F.; JUNIOR, E. F.; BUZETTI, S.; Produtividade do milho safrinha e modificações químicas de um latossolo em sistema plantio direto em função de espécies e cobertura após calagem superficial. Acta Scientiarum Agronomy, Maringá, v. 30, n. 1, p. 109-115, 2008.
ANDREOTTI, M.; SOUZA, E. C. A.; CRUSCIOL, C. A. C.; RODRIGUES, J. D,; BULL, L. T. Produção de matéria seca e absorção de nutrientes pelo milho em razão da saturação por bases e da adubação potássica. Pesquisa Agropecuária Brasileira. Brasília. V. 35, n. 12, p. 2437-2446, 2001.

BERTOL, I.; CIPRANDI, O.; KURTZ, C.; BAPTISTA, A. S. Persistência dos resíduos culturais de aveia e milho sobre a superfície do solo em semeadura direta. Revista Brasileira de Ciência do Solo, Viçosa, v. 22, p. 705712, 1998.

CARVAlHO, C. G. P.; ARIAS, C. A. A.; TOLEDO, J. F. F.; ALMEIDA, L. A.; KIIHL, R. A. S.; OLIVEIRA, M. F.; HIROMOTO, D. M.; TAKEDA, C. Proposta de classificação dos coeficientes de variação em relação à produtividade e altura da planta de soja. Pesquisa Agropecuária Brasileira, Brasília, v. 38, n. 2, p. 187 193, 2003.

CEDERGREEN, N.; FELBY, C.; PORTER, J. R.; STREIBIG, J. C. Chemical stress can increase crop yield. Field Crops Research, Amsterdam, v. 114, n. 1, p. 54-57, 2009.

COSTA, J. R.; PINHO, J. L. N.; PARRY, M. M. Produção de matéria seca de cultivares de milho sob diferentes níveis de estresse hídrico. Revista Brasileira de Engenharia Agrícola e Ambiental. Campina Grande, v 12, n. 5, p. 443-450, 2008.

FERNANDES, F. A. Persistência de palhada de plantas de cobertura em função de doses de silício e resposta do feijoeiro em sucessão. 2008. $92 \mathrm{f}$. Dissertação (Mestrado em Agronomia/Agricultura) Faculdade de Ciências Agronômicas, Universidade Estadual Paulista, Botucatu, 2008.

FERNANDES, F. A.; BULL, L. T.; CORRÊA, J. C.; CRESPAM, D .R. Influencia de silicato e calcário na decomposição de resíduos culturais e disponibilidade de nutrientes ao feijoeiro, Revista Brasileira de Ciência do Solo, Viçosa, v. 33, n. 4, 2009.

FIGUEIREDO, S. S.; LOECK, A. E.; ROSENTHAL, M. D.; AGOSTINETTO, D.; FONTANA, L. C. RIGOLI, R. P. Influencia de doses reduzidas de Glyphosate no tomateiro (Lycopersicon esculentum). Planta Daninha, Viçosa, v. 35, n. 3, p. 849-857, 2007.

FURLANI JÚNIOR, E.; ROSA, C. E.; FERRARI, S.; LUQUES, A. P. P. G.; FERRARI, J. V.; SANTOS, D. M. A.; MELLO, T. F.; QUEIROZ, A. C. P.; Efeito de subdoses de glifosato na produtividade do algodoeiro. In: CONGRESSO BRASILEIRO DO ALGODÃO, 7 ., 2009, Foz do Iguaçu. Anais... Campina Grande: Embrapa Algodão, 2009. p. 1295-1300. 
FURTADO, M. B. Sistemas de preparo do solo e populações de plantas em espaçamento reduzido: comportamento de cultivares de milho (Zea mays $\mathbf{L}$.). 2005. 87 f. Dissertação (Mestrado em agronomia/Agricultura) - Faculdade de Ciências Agronômicas, Universidade Estadual Paulista, Botucatu, 2005.

LEITE, G. H. P.; CRUSCIOL, C. A. C. Reguladores vegetais no desenvolvimento e produtividade da canade-açúcar. Pesquisa Agropecuária Brasileira, Brasília, v. 43, n. 8, p. 995-1001, 2008.

MAGALHÃES, P. C.; SILVA, J. B.; DURAES, F. O. M.; KARAN, D.; RIBEIRO, L. S.; Efeito de doses reduzidas de glyphosate e paraquat simulando deriva na cultura do milho. Planta Daninha, Viçosa, v. 19, n. 2, p. 247-253, 2001a.

MAGALHÃES, P. C.; SILVA, J. B.; DURAES, F. O. M.; KARAN, D.; RIBEIRO, L. S.; Efeito de doses reduzidas de glyphosate e paraquat simulando deriva na cultura do sorgo. Planta Daninha, Viçosa, v. 19, p. 255 262, $2001 b$.

NEVES, D. C., JUNIOR, E. F., FILHO, V. V. V. Hormese no crescimento de algodoeiro por subdoses de glifosato.. In: VII CONGRESSO BRASILEIRO DO

ALGODÃo, Foz do Iguaçu. Anais... p. 915 a 922, 2009.

PAVINATO, P. S.; ROSOLEM, C. A. Disponibilidade de nutrientes no solo - decomposição e liberação de compostos orgânicos de resíduos vegetais. Revista

Brasileira de Ciência do Solo, Viçosa, v. 32, n. 3, 2008.

PIMENTEL GOMES, F. Curso de Estatística Experimental. 12. ed. Piracicaba: Nobel, 1990. 468 p. POSSAMAI, J. M.; SOUZA, C. M.; GALVÃO, J. C. C.; Sistemas de preparo do solo para o cultivo do milho safrinha. Bragantia, Campinas, v. 60, n. 2, 2001.

RIQUETTI, N. B. Efeito do manejo de solo nos parâmetros agronômicos e energéticos de híbridos de milho transgênico e não transgênico. 2011. $73 \mathrm{f}$. Dissertação (Mestrado em Agronomia /Energia na Agricultura)- Faculdade de Ciências Agronômicas, Universidade Estadual Paulista, Botucatu, 2011.

SANTI, A.; AMADO, T. J. C.; ACOSTA, J. A. A. Adubação nitrogenada na aveia preta. Influência na produção de matéria seca e ciclagem de nutrientes sob sistema plantio direto. Revista Brasileira de Ciência do Solo, Viçosa, v. 27, p. 1075 - 1083, 2003.

SILVA, M. A.; ARAGÃO, N. C.; BARBOSA, M. A; JERONIMO, E. M.; CARLIN, S. D. Efeito hormótico de gliphosate no desenvolvimento inicial de cana de açúcar. Bragantia, Campinas, v. 68, n. 4, 2009.
SILVA, A. R. B da. Diferentes sistemas de manejo do solo e espaçamentos na cultura do milho (Zea mays L.) 2004. 147p. Tese (Doutorado em Agronomia - Área de Concentração Energia na Agricultura) - Faculdade de Ciências Agronômicas, Universidade Estadual Paulista, Botucatu, 2004.

SILVA, J.C.; ARF, O.; GERLACH, G.A.X.; KURYIAMA, C.S.; RODRIGUES, S.A.F. Efeito hormese de glyphosate em feijoeiro, Pesquisa Agropecuária Tropical, Goiânia, v. 42, n. 3, p. 295302, 2012.

SILVA, P. I. B. ; FERREIRA, L.R.; REIS, W.F.; COELHO, A.T.C.P.; GONÇALVES, V.A.; MORAES, FELIPE, R. S.; Acumulo de matéria seca de milho e braquiaria consorciados em diferentes manejos de plantas daninhas. In: XXVII Congresso Brasileiro de Plantas Daninhas, Ribeirão Preto, Anais... p. 2351-2353, 2010.

SOUTHAM, C. M.; EHRLICH, J. Effects of Extract of western red-cedar heartwood on certain wood-decaying fungi in culture. Phytopathology, St Paul, MN, EUA, v. 33 , p. 517-524, 1943.

TUFFI SANTOS, L. D.; FERREIRA, F. A.; FERREIRA, L. R.; DUARTE, W. M.; TIBEURCIO, R. A. S.; SANTOS, M. V.; Intoxicação de espécies de eucalipto submetidas à deriva do glyphosate. Planta Daninha, Viçosa, v. 24, n. 2, p. 359-364, 2006.

VELINI, E. D.; ALVES E.; GODOY, M. C.; MESCHEDE, D. K.; SOUZA, R. T.; DUKE, S. O.; Glyphosate applied at low doses can stimulate plant growth. Pest Management Science, Hoboken, v. 64, n. 4, p. 489-496, 2008.

YAMASHITA, O. M.; GUIMARÃES, S. C. Resposta de cultivares de algodoeiro a subdoses de glyphosate. Planta Daninha, Viçosa, v. 23, n. 4, p. 627-633, 2005.

YAMASHITA, O. M.; GUIMARÃES, S. C. Deriva simulada de glyphosate em algodoeiro: efeito de dose, cultivar e estádio de desenvolvimento. Planta Daninha,v. 24, n. 4, p. 821-826, 2006. 